\title{
ANAESTHETIC TECHNIQUES AND THE “OPEN CHEST”*
}

\author{
RENÉ LÉTIENNE, M.D., F.R.C.P. (c) *
}

"OPEN CHEST" anaesthesıa brings together so many factors, requirements and means to deal with them, that a presentation of definite opinions is hardly justified when considering proper anaesthetic techniques for surgical thoracic patients. Simple solutions to some complex problems have yet to be found, notwithstanding an abundance of avallable drugs, methods, and apparatus $(1,2)$.

Even after careful investgation and estmation, patients with seemingly adequate functional reserves will be encountered who are not fit to resist actual conditions of anaesthesia and stress. Their general condition will deteriorate rapidly during induction or soon after a lung is allowed to collapse, and they will not respond to ordinary corrective measures. The value of assessing vital functions in conscious patients (3), not submitted to the actions of depressant drugs, is inestimable, but the information is never so exhaustive as to make possible absolute competence for anaesthesia and its associated risks of hypoxia. It is also important to remember that, during the course of anaesthesia, unusual responses are frequent and that conventional treatment, based on studies of conscious patients, does not necessarily correspond or may not be sufficient, (4).

With some knowledge of the proposed operation and the mode of performing it, watching its progress in detal greatly facilitates the task of both surgeon and anaesthetist, who should thoroughly understand each other's problems, so that control of ventilation, of secretions, of haemorrhage, of reflex activity will also provide for access to pathology, its exploration and treatment.

It is clear that normally the technique which the anaesthetist knows best and which he can most skilfully employ should be his logical choice. However, many will indulge (beginners probably being more prone to temptation) in a hodgepodge of anaesthetic acrobatics, under the impression that flashy performance, which cannot disguise a flagrant lack of clinical judgment and undigested theories, is evidence of worthy achievement. Unfortunately, the patient always pays a stiff price for such bluffing. Trifling with procedures which are too difficult to perform and which cannot remain under full control of the anaesthetsst probably leads to more inefficiency than rigid adherence to blind routne Variants of many procedures can be adopted but one must keep in mind the hazards to be overcome and avoid, if possible, techniques liable to jeopardize physiological equilibrium.

\section{Methons}

General anaesthesia by the closed method is now commonly used. Regional methods have been supplanted because they do not allow enough regulation of the risks of an "open chest." Topical anaesthesia and local infiltration of sensory

"From a Panel Discussion on "Anaesthesia and the Open Chest," held, under the direction of Dr. S. M. Campbell, at the Annual Meeting of the Canadian Anaesthetists' Society in the Banting Institute of the University of Toronto, June 20, 21, and 22, 1955.

*Notre Dame Hospital, Montreal, Que. 
and reflex zones contribute to safer anaesthesia. Familiarity and experience with surface analgesia would perhaps be more acceptable to anaesthetists at large if it is recognized that intubation of dyspnoeic patients or of "wet cases" is likely to be safer when performed correctly on conscious patients.

\section{AgENTS}

Selection of agents depends manly on their pharmacological actions in relation to the patient's general condition, on the use of diathermy, and on the constant need for satisfactory oxygenation. In this latter respect, oxymetric studies have at least shown that the clinical eye is a poor judge of blood-oxygen saturation and that human organısms frequently exhibit an amazing resilience when submitted to oxygen famme. One notable adjunct in recent years has been the introduction of neuro-blocking drugs which decrease reflex activity durng ana esthesia and possibly reduce postoperatively the incidence of atelectatic complications of neuro-vegetative origin. The protective mechanisms of cough and consciousness should return with the termunation of the operation as they remain, by far, the least traumatic and the most efficient means of securing broncho-pulmonary toilet and satisfactory expansion of the lung tissue. Bronchoscopy is a possible necessity immediately before, during, or after operation and equipment for bronchoscopy and aspiration should always be available. It may be mandatory before surgery for very wet cases or for those suffering trom severe thoracic injuries. If at all teasible, it should be performed under topical analgesia, the dangers of bronchoscopy under general anaesthesia being only too well known. Should the procedure be protracted and the patient be in a state of exhaustion, it is safer to postpone surgery as attempts to induce general anaesthesia may be extremely risky.

\section{EQQUTPMENT}

The imposing array of equpment used in conjunction with thoracic anaesthesia is made necessary because it is difficult to satisfy simultaneously the exigencies of physiology, of dynamics, and of anatomy.

Several important considerations appear in combination: prevention of paradoxical breathing and mechanical flap, of coughing and buckng, and of pathogenic spreading, while allowing for adequate gaseous exchange and aspiration of bronchial fluids. These requisites must be satisfied without undue perturbations of the cardiovascular functon, without initiating autonomic reflex phenomena, and under an even plane of anaesthesia which will also allow for rapid recovery.

The use of endotracheal tubes is indispensable in "open chest" anaesthesia, even if they sometmes cause damage to tracheal structures and are a frequent source of noxious reflexes. The importance of this autonomic hyperactivity has been somewhat exaggerated at times (5), the E.C.G. changes especially, because of their fleeting character and because it is now possible to regulate them by nerve-blocking methods. Certainly, they ${ }^{3}$ do not take precedence over respiratory safety and control.

Desirability for a leak-proof airway has led to the use of large-bore tubes, pharyngeal packs, and inflatable cuffs. Trans-thoracic operations not involving 
the air passages directly are now commonly performed with the assistance of cuffed endotracheal tubes, as are operations for lung surgery of the "dry type." Exceptions are mainly in the case of air cysts of the lungs, gross anatomical deformities and, of course, with children.

In "wet cases," it must be realized that cuffed tubes may act as a dam to retain bronchial fluids between the catheter and the tracheal wall, with a risk of directing the overflow of secretions into another lobe or lung. Beecher (2), in a very convincing way, favours the use of intermediate-sized tubes which lie free under an ordinary face mask for total or partial lung resections, relying on posture and suction to check secretions and spread of disease from healthy tissue (Figure 1).

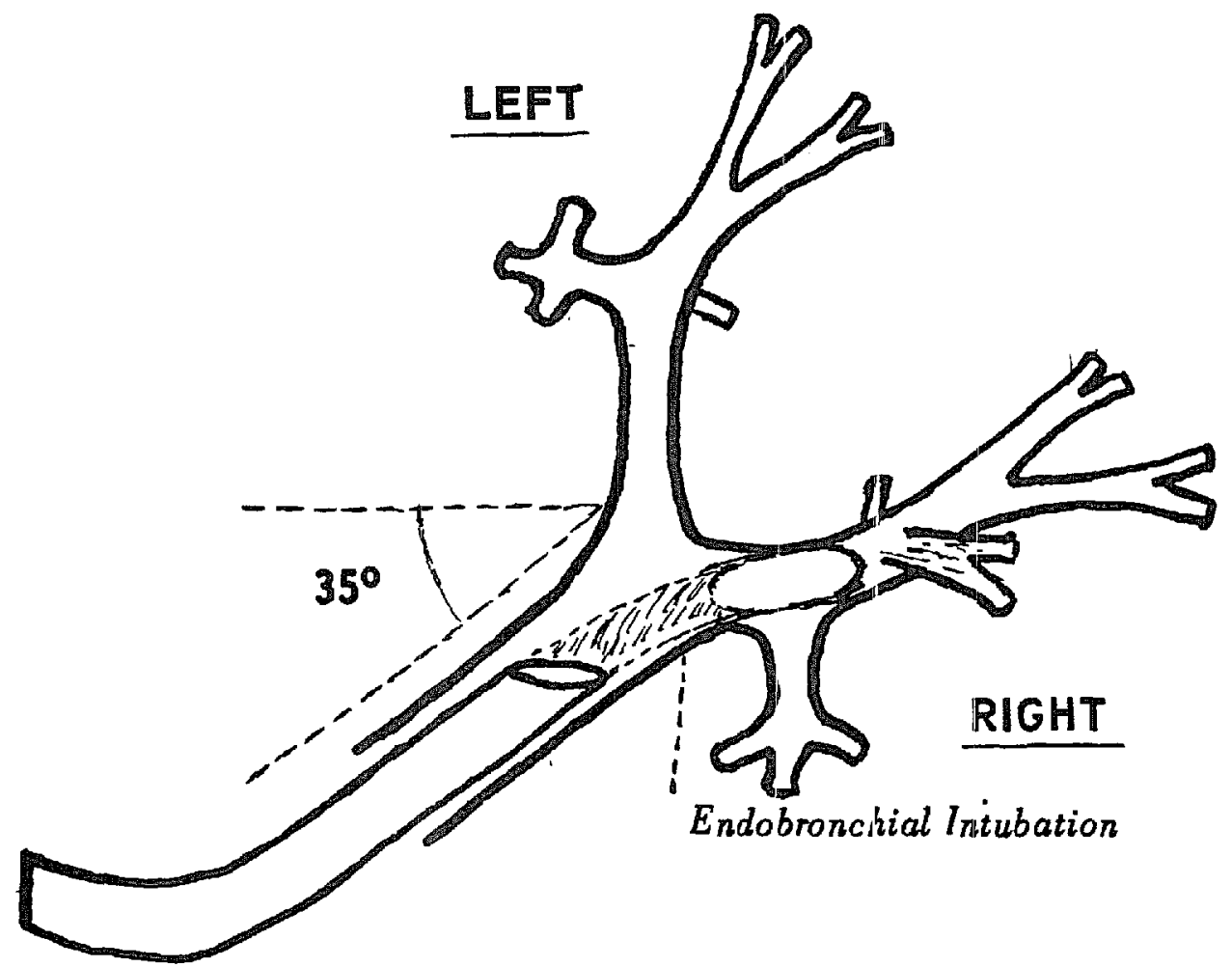

Figure 1. Left Thoracotomy in lateral position gravity dramage A $10^{\circ}$ thlt is adequate in the prone (Overholt) position.

The case against systematic use of inflatable cuffs is obvious and sound reasons only warrant their use. Likewise, when control of secretions and ventilation stands as a major problem from the anaesthetic point of view, justification for the use of other methods should logically be subordinate to the greater advantages which these can actually procure.

If postural drainage and suction associated with endotracheal techniques are deemed insufficient for particular cases, separate lung anaesthesia or segmental blocking permitting drainage or inflation of localized pulmonary areas can prove most convenient. But the multitude of methods advocated to achieve satisfactory endobronchial anaesthesia is a fair gauge of their present status in respect to efficacy and practicability. This does not mean that these techniques are to be neglected, for, when they are indicated and feasible, they definitely add to the safety of certain operations, specifically in the presence of broncho-pleural fistula, 
of copious suppuration, of pulmonary cysts, or for pneumonectomies or lower lobe resections. For upper lobectomies or where anatomical abnormalities exist, such procedures are still not consistently satisfactory, even in the hands of the very skilled.

Unilateral bronchial intubation of the main bronchus of a healthy lung and bronchial tamponage are now seldom performed on account of their many shortcomings Bronchial occlusion with a cuffed suction catheter of the Thompson or the Magill type is theoretically ideal both from an anaesthetic and from a surgical angle, but it is difficult to perorm (Figure 2). A blocker can easily slip out of

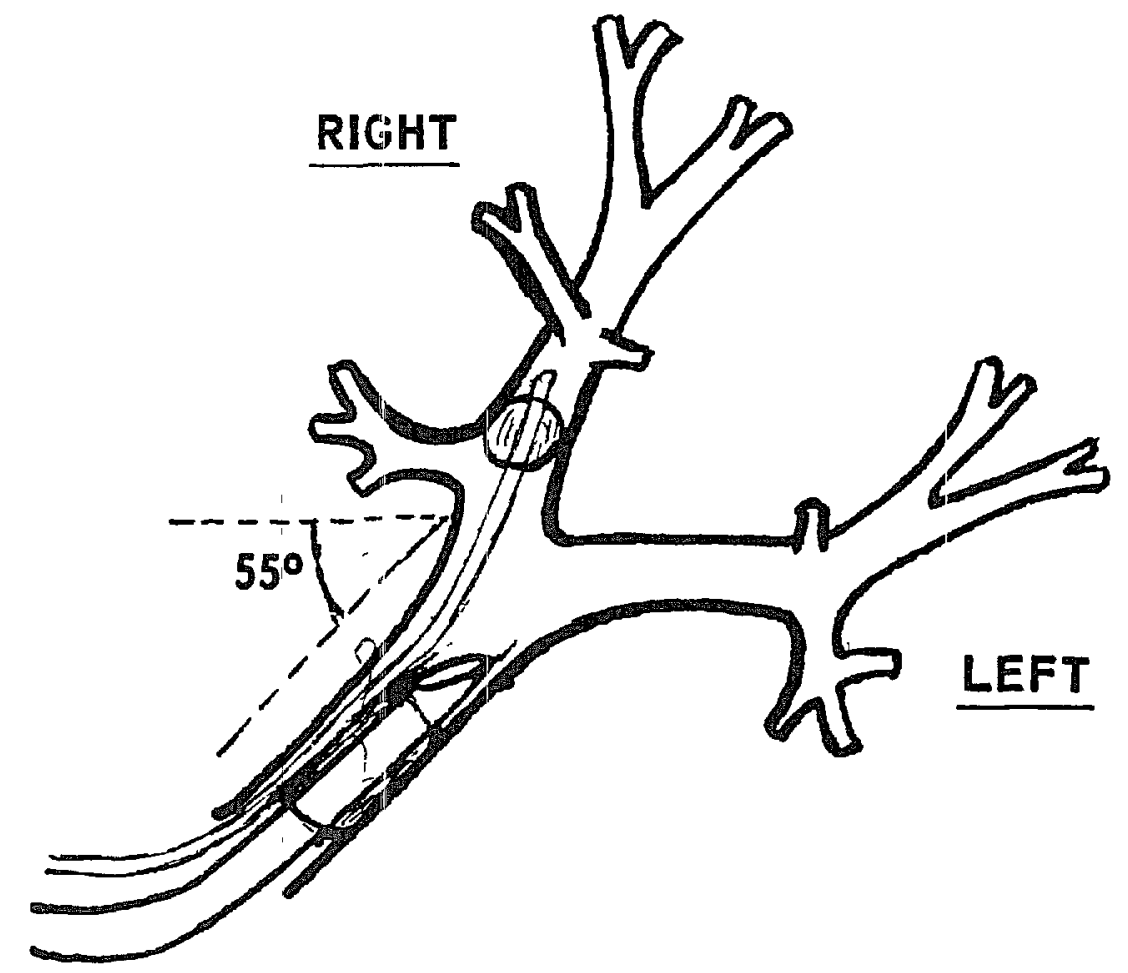

Figure 2. Gravity drainage for nght thoracotomy. This extreme position is not necessary with bronchial block and suction.

place; because it is separate from the endotracheal tube and placed alongside of it, an air-tight fit may not be obtained. An endotracheal tube incorporating an endobronchial blocker, devised by Sturtzbecher (6), assures a more leak-proof system but, otherwise, this modification presents the same disadvantages and middle or upper blocking remains even harder to carry out.

Carlens' endobronchial tube (7) is probably the best answer to this singularly intricate problem (Figure 3). Its introduction is not too exacting for the patient or the anaesthetist; it is adaptable to most cases where its use could be advantageous and serves well the purposes of one-side anaesthesia, since it makes possible segmental inflation and deflation, or suction, while an even, uninterrupted plane of anaesthesia is maintained. It also srovides a rather easy way to adapt one's task to surgical requirements. The ae_odynamic properties of this doublelumen tube have been studied $(8,9)$ under various circumstances and results of 


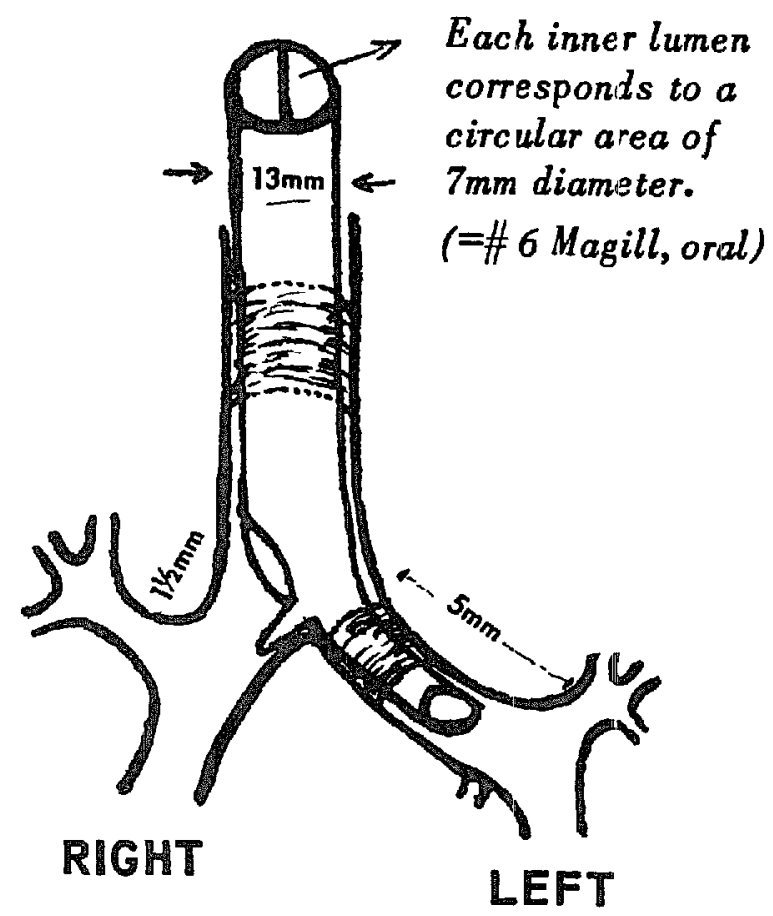

Carlens' tube permits bilateral bronchial control for isolation, suction, and insufflation.

experiments on resistance to breathing indicate that its routine use for all thoracic cases might be questionable However, at low rates of flow, resistance to air passage is greatly minimized if controlled respiration is used and physiological disturbances are negligible or absent.

\section{SUMMARY}

Solution of the manifold technical problems associated with anaesthesia for "open chest" surgery depends primarly on a tholough understanding of the physiological and mechanıcal aspects involved. Too strict adherence to any standardized routine may spell failure if each patient and each surgical demand? are not clearly recognized by each anaesthetist.

Endotracheal and endobronchial general anaesthesia have displaced other methods. Drugs and equipment to carry out these techniques are numerous but are of limited assistance in providing a perfect answer to meet the challenge. The arm-chair or the floor-walker type of anaesthetist stands to gain immeasurably in experience and skill by close study and minute-to-minute observation of patients submitted to this form of anaesthesia.

\section{RÉSUMÉ}

A cause des nombreux problèmes de physiologie, de dynamique et d'anatomie qu'elle soulève, il n'est pas facile de trouver une formule simplifiée si l'on considère les techniques anesthésiques employables en chirurgie thoracique transpleurale. L'anesthésie générale, par voie endotrachéale ou endobronchique, a 
supplanté les autres méthodes, parce qu'elle permet un meilleur contrôle des perturbations physio-pathologiques et des risques inhérents à ces interventions. L'anesthésie endotrachéale suffit dans l'immense majorité des, cas. Où il y a danger de contamination ou d'inondation des voies respiratoires, les méthodes endobronchiques s'imposent plus particulièrement, surtout au moyen du tube Carlens.

Drogues, méthodes et apparellage n'ont d'importance qu'en autant qu'ils sont utilisés à bon escient, par un anesthésiste sérieux et expérimenté. Les techniques destinées à épater les badauds, mais qui dépassent l'habilité de ceux qui s’amusent à s'en servir, taxent injustement l'opéré et n'ont aucun droit de cité.

\section{REFERENCES}

1 Mushin, W H. \& Rendell-Baker, L Prnnciples of Thoracic Anaesthesia Springfield, Ill.: C. C Thomas (1953).

2 Beecher, H. K Principles, Problems, and Practices of Anesthesia for Thoracic Surgery. Springfield, Ill . C. C Thomas (1952).

3 Comroe, J. H. \& Blackmons, W. S. The Diagnostic and Prognostac Value of Pulmonary Function Tests. Surg. Clin North Amer 291671 (1949).

4 Fisher, $\mathrm{K}$ \& Winsor, $\mathrm{T}$ Contributions of Electrocardiography to Anesthesia for Chest Surgery. Anesthesiology 13147 (1952).

5 Converse, J G, Landmesser, C M \& Harmel, M H Electrocardiographic Changes during Extubation A Study of Electrocardrographic Patterns during Endotracheal Anesthesia including those seen during Intubation, Endotracheal Suction, and particularly Extubation Anesthesiology 13. 163 (1952).

6 ОЕсн, S R. A Cuffed Endotracheal tube with an Incorporated Endobronchial Blocker. Anesthesiology 16468 (1955).

7 Bjork, V O, Carlens, E \& Fribug, O Endobronchial Anesthesia Anesthesiology 1460 (1953).

8 Mackreli, T N Resistance study with the Carlens-Stılle Double Lumen Endotracheal Catheter. Ahesthesiology 15209 (1954).

9 Orkin, L. R, Stegel, M \& Rovenstine, E A. Resistance to Breathing by Apparatus used in Anesthesia Anesth \& Anal 33217 (1954) 